\title{
Errata: Search and detection comparing midwave and longwave infrared
}

Tana Maurer, MEMBER SPIE

David L. Wilson, MEMBER SPIE

Stevie R. Smith, MEMBER SPIE

Dawne M. Deaver

Eric A. Flug

Oanh Tho Nguyen

U.S. Army Research

Development and Engineering Command

Night Vision and Electronic Sensors Directorate

10221 Burbeck Road

Fort Belvoir, Virginia 22060

This article [Opt. Eng. 48, 116401 (2009)] was originally published on 16 November 2009 with errors in the order of authors listed. Stevie R. Smith should have appeared third instead of first on the list. All versions of the article were corrected on 18 November 2009 and the article appears correctly in print. 